Mersch, Margit, Ritzerfeld, Ulrike, Lateinischgriechisch-arabische Begegnungen. Kulturelle Diversität im Mittelmeerraum des Spätmittelalters

\title{
Benoît Grévin
}

\section{(2) OpenEdition}

Édition électronique

URL : http://journals.openedition.org/ifha/6613

DOI : 10.4000/ifha.6613

ISSN : 2198-8943

Éditeur

IFRA - Institut franco-allemand (sciences historiques et sociales)

\section{Référence électronique}

Benoît Grévin, « Mersch, Margit, Ritzerfeld, Ulrike, Lateinisch-griechisch-arabische Begegnungen Kulturelle Diversität im Mittelmeerraum des Spätmittelalters », Revue de l'IFHA [En ligne], Date de recension, mis en ligne le 01 janvier 2011, consulté le 22 septembre 2020. URL : http:// journals.openedition.org/ifha/6613; DOI : https://doi.org/10.4000/ifha.6613

Ce document a été généré automatiquement le 22 septembre 2020.

(CIFHA 


\title{
Mersch, Margit, Ritzerfeld, Ulrike, Lateinisch-griechisch-arabische Begegnungen. Kulturelle Diversität im Mittelmeerraum des Spätmittelalters
}

\author{
Benoît Grévin
}

Ce volume regroupe les actes d'un atelier tenu en 2006 à Erlangen sous le titre « Aspects de la cohabitation interculturelle dans la méditerranée tardo-médiévale : témoignages artistiques, architecturaux et textuels ». Les contributions concernant l'histoire de l'art, il eût été plus pertinent de choisir pour la publication un titre moins vague. Derrière ces « Rencontres latino-gréco-arabes. Diversité culturelle dans l'espace méditerranéen du bas Moyen Âge ", se cache en effet un ensemble de réflexions sur la circulation des motifs artistiques entre Byzance, le monde arabe et la méditerranée latine, avec un fort accent mis sur l'Italie, en particulier du Sud, des XIIe-XVe siècles. Après une double introduction problématique (M.M., " Kulturelle Diversität im Mittelmeerraum des Spätmittelalters », p. 9 ; U.R., " Zu Problematik und Erkenntnispotential der Untersuchungen materieller bzw. visueller Kulturen im Mittelmeerraum »), on peut opposer un ensemble de quatre communications suditaliennes (G. Wolf, " Alexandria aus Athen ? Perspektiven einer mediterranen Kunstgeschichte mit einem Seitenblick auf das mittelalterliche Sizilien », p. 39-62 ; V. Bianchi, «I musulmani nel sud Italia. Scontri, monstri, reciprocità », p. 181-198 ; D. Heißenbüttel, « Indizien kultureller Differenz in den mittelalterlichen Bau-, Bild- und Schriftdenkmalen aus Bari und Matera. Ein Schichtenmodell », p. 199-218; M. Mersch et U. Ritzerfeld, « Lateinisch-griechische Begegnungen in Apulien. Zur Kunstpraxis der Mendikanten im Kontaktbereich zum orthodoxen Christentum ", p. 219-284, à un groupe plus erratique comprenant une étude sur la circulation des récipients de luxe (M. Georgopoulou, «Fine Commodities in the Thirteenth-century Mediterranean. The Genesis of a Common Aesthetic », p. 63-89), des motifs héraldiques (R. Ousterhout, " Symbole der Macht. Mittelalterliche Heraldik zwischen Ost und West », p. 91-110), des reliques vénitiennes de provenance byzantine (K. Krause, «Feuerprobe, Portraits in 
Stein. Mittelalterliche Propaganda für Venedigs Reliquien aus Konstantinopel und die Frage nach ihrem Erfolg ", p. 111-16), des motifs byzantins dans la Bible de Gérone (A. Hoffmann, « Leibsfülle zwischen Ost und West. Beobachtungen zur Byzanz- und Antikenrezeption in der Bibel von Gerona ", p. 163-180), enfin des représentations textuelles et visuelles des prédications mendiantes en Islam (A. Müller, « Bettelmönche und Islam. Beobachtungen zur symbolischen Darstellung von Missionsprinzipien der Mendikanten in Text, Handlung und Bildkunst des 13. Jahrhunderts ", p. 285-308). En dépit des limites inhérentes à tout ouvrage collectif, la concentration sur l'Italie comme lieu de transit de motifs artistiques et la bonne tenue d'ensemble de communications qui ne négligent pas une réflexion épistémologique interdisciplinaire (notamment en direction de l'histoire textuelle) font de ces Rencontres un apport réel dans le champ fort encombré de l'histoire des contacts inter-méditerranéens. On se contentera de déplorer la récurrence d'un ou deux clichés qu'il faudrait définitivement évacuer (G. Wolf, p. 59, prolongeant l'interminable mythe de la " cour palermitaine de Frédéric II ", qui n'a passé que cinq mois à Palerme entre 1212 et $1250 . .$.$) , ou de considérations$ moralisantes oiseuses dans une réflexion historique (toujours sur Frédéric II, dans la communication par ailleurs riche de V. Bianchi, p. 187).

Benoît Grévin (CNRS, Laboratoire de médiévistique occidentale

de Paris) 